\title{
O PAPELDO MARKETING NA CONSTRUÇÃO DE UMAAGENDA AMBIENTAL: REFLEXÕES A PARTIR DE ESTUDO DE CASO DE UMA GESTÃO PÚBLICA
}

OLIVIO, Dennis Henrique Vicário. Centro Universitário de Araraquara - Uniara. Rua Manaus, 270, Centro. CEP 15.800-260, Catanduva-SP. E-mail: dennis@ odyn.com.br.

FERRANTE, Vera Lúcia Botta. Centro Universitário de Araraquara - Uniara. Rua Dr. Arlindo Soares de Azevedo, 82 - Santana. CEP: 14.801-415, Araraquara-SP. E-mail: vbotta@techs.com.br.

\begin{abstract}
RESUMO
O presente trabalho - um estudo de caso - discute a construção de uma agenda ambiental em uma gestão pública relacionando este processo ao marketing utilizado no município de Catanduva, Estado de São Paulo. Seu objetivo é avaliar a importância do emprego das técnicas e métodos da comunicação como mecanismos de interação humana que se relacionem com as questões ambientais, e se houve algumas mudanças por parte da população a partir da contratação de uma agência de marketing. Para tanto, desenvolveu-se uma série de pesquisas baseadas no registro das campanhas ambientais promovidas pela Superintendência de Água e Esgoto de Catanduva - Saec com os principais atores envolvidos: agência de comunicação, poder público municipal e, posteriormente, a população e os formadores de opinião do município. A metodologia utilizada abrangeu a consulta aos dados da Saec sobre consumo de água nos períodos anteriores e posteriores às campanhas ambientais realizadas em Catanduva, questionários aplicados em dois bairros da cidade, de composição socioeconômica distinta. Foram igualmente entrevistados agentes da gestão pública que têm atuação direta ou indireta na questão ambiental, lideranças de bairros, dentre outros. Dessa forma, foi possível aferir que as políticas públicas municipais recorrem constantemente ao marketing para auxiliar na condução de processos de conscientização ambiental, mas, infelizmente, o processo ainda é deficiente e grande parte das ações não atinge seus objetivos primários. Nesse sentido, é possível concluir que as políticas públicas locais, mesmo se utilizando de marketing, têm avançado muito pouco na conscientização dos cidadãos sobre as necessidades de mudanças de hábitos face às questões ambientais.
\end{abstract}

Palavras-chave: Meio ambiente, Políticas públicas municipais; Marketing ambiental; Conscientização ambiental local; Gestão de Catanduva.

\begin{abstract}
This paper - a case study discusses - the construction of an environmental agenda in a public managing relating this process to the marketing used in the city of Catanduva, São Paulo state. Its aim is to evaluate the importance of the use of techniques and communication methods as mechanisms of human interaction related to environmental questions and if hiring a marketing agency has produced some changes in the people. With this aim, a series of researches was developed based on the register of the environmental campaigns promoted by the Water and Sewage Treatment Sector of Catanduva (Superintendência de Água e Esgoto de Catanduva - Saec) with the main involved actors: the communication agency, the local public power, and later, the people and the opinion formers in the city. The adopted methodology involved consulting the Saec data about water consume in the periods which preceded and succeeded the environmental campaigns which took place in Catanduva and questionnaires applied in two sections of the city, with different socioeconomic composition. We also interviewed public management agents, who were directly or indirectly involved in the environmental question, section leaders, among others. This way it was possible to verify that public local policies frequently use marketing to help in the conduction of environmental awareness processes, but, unluckily, the process is still deficient and
\end{abstract}


great part of the actions doesn't reach their primary objectives. It is possible to conclude that local public policies, even using marketing, have made little progress in making citizens aware of the necessities of habit changes in environmental issues.

KEYWORDS: Environment; Local public policies; Environmental marketing; Local environmental awareness; Management of Catanduva.

\section{INTRODUÇão}

É possível perceber nos últimos anos que o Estado vem-se articulando e se inter-relacionando com os demais setores sociais na busca de mecanismos que permitam ampliar a difusão de uma nova consciência ecológica, seja na adoção de políticas públicas, seja na intensificação do seu caráter intervencionista e fiscalizador. É um processo complexo que se modifica conforme a capacidade dos atores envolvidos de interagir de forma democrática, realista e racional. A soma dessas ações pode contribuir, gradativamente, para a formação da consciência ambiental do cidadão comum e, em médio prazo, pode interferir na qualidade de vida do indivíduo e da sua comunidade.

$\mathrm{Na}$ busca de mecanismos de ação social que interajam e se relacionem com o ser humano, alguns autores consideram a educação como o principal meio disseminador de ideias, atitudes e hábitos que visam ao respeito ao meio ambiente. Capra apud Trigueiro (2008) considera que ensinar o "saber ecológico" será o papel mais importante da educação no século 21 . Contudo, como cita Giacomini (2008), a transmissão desse saber, por ser um processo contínuo, de resultados em longo prazo, ainda se apresenta em vias de maturidade e pode não corresponder à urgente necessidade de ação.

Diante dessa perspectiva, Andreasen (2002), dentre outros autores - como Caetano (2008), Dias (2008) e Ottman (2004) - cita que o marketing, principalmente através da propaganda, pode contribuir, se conduzido por agentes que buscam a equidade na relação homem e meio ambiente, para a intensificação das ações da educação ambiental em todos os níveis, atuando como agente fomentador de cultura, da ética e da conscientização ambiental.

Diante dessa possibilidade, é inquestionável que o Estado, em todas as suas esferas, ao cumprir seu papel social na adoção de políticas socioeducativas, se utilize também das ferramentas de comunicação para atingir seus objetivos. Contudo, as ações de comunicação ambiental adotadas pelo setor público no Brasil ainda são superficiais quando comparadas às necessidades concretas e urgentes que se apresentam. As mensagens dessas ações priorizam o conteúdo informativo das instituições públicas, como divulgação de obras e projetos ambientais executados, e poucas vezes direcionam seus esforços para o processo de conscientização ambiental. Na esfera municipal, verifica-se que as governanças locais têm dificuldades em formar parcerias com os demais setores sociais, e acabam focando seus esforços de forma isolada ou em continuidade a programas e ações de esferas governamentais superiores.

Contudo, é circunstancial para o processo de conscientização ambiental que as políticas públicas municipais direcionem seus esforços, por meio das mais diversas alternativas, para transferir ao cidadão a compreensão à problemática de uma realidade que lhe pertence (o problema local), para posteriormente fomentar a conscientização em uma esfera macro, na qual, em curto e médio prazos, nem sempre o cidadão é atingido diretamente pelo problema.

Sendo assim, este artigo tem como propósito levantar o papel do setor do marketing na construção de uma agenda ambiental no município de Catanduva, bem como as perspectivas de as políticas municipais alavancarem a conscientização da população em relação aos problemas ambientais.

Vale ressaltar que a possibilidade de investimentos em ações ambientais é praticamente nula na maioria dos municípios brasileiros. Os poucos municípios que dispõem de recursos ou que, efetivamente, precisam tomar medidas emergenciais locais para a contenção de algum tipo de atividade, necessitam saber se o investimento em comunicação traz resultados para seus objetivos. Mais do que isso, o método publicitário exige 
que o gestor municipal compreenda uma série de variantes que muitas vezes não fazem parte de sua prática profissional, fato que leva ao fracasso grande parte das ações promovidas e, consequentemente, ao desperdício do investimento público.

Dessa forma, este estudo se justifica pela necessidade eminente do setor público municipal em gerenciar suas ações de modo mais coeso, por meio de informações relevantes que auxiliem na tomada de decisões de cunho ambiental e comunicacional do setor. Ainda mais, propõe-se a subsidiar a agenda das políticas públicas, mostrando a importância da efetiva inclusão das questões ambientais dentre as prioridades de ação.

\section{OS CAMINHOS DA METODOLOGIA}

Inicialmente, optou-se por levantar a abordagem teórica do marketing que o caracteriza e o identifica como marketing verde ou ambiental. Os autores mais representativos deste levantamento são: Kotler (1992 e 1999); Santa`Anna (1998), Fontes (2008); Dias (2008), Caetano (2008); Giacomini Filho (2004) e Sina (1999).

A produção teórica sobre marketing mostrou vazios no que tange às relações entre comunicação e poder local e é extremamente restrita enquanto abordagem, pois invariavelmente é direcionada à gestão empresarial. No entanto, alguns autores contribuíram significativamente para o entendimento do papel do marketing para a tomada de decisões do setor público, entre eles: Antoniosi (2005), Kotler (2008), Manhanelli (2004), Rego (2005) e Trigueiro (2008).

Diante da escassez de referencial teórico que contemplasse as relações existentes entre as temáticas estudadas, foi perceptível desde o início desta pesquisa que a elucidação de algumas questões propostas dependeria, diretamente, do levantamento de informações por meio de entrevistas com os principais atores sociais envolvidos com as ações de marketing ambiental do município: Departamento de Comunicação da Prefeitura de Catanduva, órgão municipal responsável pelo investimento em comunicação no município; Secretaria de Meio Ambiente, órgão municipal promotor das ações de comunicação no município; e a agência Odyn Comunicação.

Contudo, no início do processo de levantamento de dados, foi possível notar que a Secretaria de Meio Ambiente não tinha estrutura lógica de informações que possibilitassem um estudo quantitativo e qualitativo de suas ações de marketing ambiental. Também foi perceptível, por meio de conversas informais, que a secretaria não considera relevantes os problemas ambientais do município e, talvez por este motivo, não concentra seus esforços em ações específicas de educação ou preservação ambiental.

Em contrapartida, a então Secretaria de Saneamento Básico de Catanduva, hoje Saec, na figura do superintendente, mostrou grande interesse em contribuir com as pesquisas e, diferentemente da Secretaria do Meio Ambiente, o gestor possuía dados de consumo de todas as regiões da cidade, que possibilitariam a aquisição de dados empíricos para $o$ projeto, através de análises de consumo e diagnósticos da percepção das populações residentes em áreas de alto consumo sobre a água. Após análise da situação, foi estabelecido um novo recorte no objeto da pesquisa, delimitando-a, a partir de então, apenas às ações de marketing ambiental desenvolvidas pela superintendência.

O processo de coleta de dados com a Saec teve seu início a partir do levantamento exploratório das ações da superintendência que empregaram algum tipo de ferramenta de comunicação no período de 2006 a 2009. O levantamento das ações ocorridas entre 2006 e 2008 foi realizado junto à Assessoria de Comunicação do município, que até 2008 era o órgão responsável pelas ações do setor. Já as ações ambientais desenvolvidas no ano de 2009 foram levantadas junto à própria superintendência.

Posteriormente, as ações foram catalogadas como cases e divididas em grupos, de acordo com seus objetivos de comunicação, com finalidade de avaliar e comparar o planejamento, investimento e abrangência de cada grupo de ações. Das 18 ações desenvolvidas pelo órgão, foi possível identificar que apenas 7 delas tiveram como objetivo algum nível de conscientização 
ambiental. Uma vez identificadas, foi realizado o levantamento dos dados de planejamento das campanhas junto à agência Odyn Comunicação. Esses dados possibilitaram a adição das seguintes variáveis ao trabalho: investimento, período, objetivos, meios utilizados, público-alvo, abordagens e peças das campanhas.

Posteriormente, foram aplicadas duas entrevistas semiestruturadas com o superintendente da Saec e uma entrevista semelhante com o diretor de Planejamento da agência Odyn Comunicação. As entrevistas tiveram como objetivo propiciar o conhecimento da estrutura e funções da Saec, além de levantar procedimentos, meios, técnicas, bem como a importância do uso das ferramentas de comunicação para a divulgação das ações da entidade. Assim, foi possível identificar, no contexto do poder público, as particularidades da comunicação ambiental.

A superintendência forneceu também a tabela de consumo mensal de todos os bairros do município no período de 2006 a 2009. Diante das informações de consumo dos bairros foi possível identificar, junto à Saec, duas regiões do município díspares quanto a hábitos, poder econômico e nível educacional, que apresentavam altas taxas de consumo de água: o Bloco 11 - região de distribuição de água composta pelo bairro Residencial Pachá e parte de bairros vizinhos e os Blocos 1 e 2 - região central da cidade.

Depois de identificados os setores que representariam a população local, foram aplicados questionários semiestruturados, compostos por 26 questões, em 100 chefes de domicílio nos dias 1, 8, 15, 22 e 29 de agosto de 2009.

Optou-se por uma amostra não probabilística acidental, uma vez que já eram conhecidas as características da população.

Para potencializar a possibilidade de encontrar o chefe de domicílio em sua residência, todas as entrevistas foram realizadas no sábado durante o período da manhã. A escolha do dia da semana foi fundamental para a rápida conclusão dos trabalhos de pesquisa de campo, uma vez que $82 \%$ dos chefes foram encontrados em seus domicílios.
A pesquisa teve como objetivos a identificação do impacto das ações de marketing ambiental da Saec para a população; a percepção da população quanto à conscientização do uso racional da água; detectar possíveis fatores que teriam ocasionado as altas taxas de consumo registradas; identificar as deficiências e potencialidades das ações até então aplicadas e os principais meios de comunicação e/ou agentes sociais capazes de atingir essas populações.

Inicialmente, era também proposta da pesquisa levantar os dados empíricos de consumo de água nas residências entrevistadas. No entanto, os munícipes nem sempre guardavam seus comprovantes de pagamento dos meses anteriores à pesquisa. Dessa forma, optou-se por ignorar os dados de consumo dos entrevistados e manter apenas os dados de consumo geral dos blocos.

Posteriormente à pesquisa de campo, foram identificadas junto à Secretaria Municipal de Planejamento e à Saec as lideranças locais dos bairros pesquisados. Essas lideranças (diretores de escola, presidentes de clubes e associações de moradores e líderes religiosos) responderam, nos meses de setembro e outubro de 2009, a um questionário aberto, composto por 12 questões, com a finalidade de avaliar o nível de envolvimento desses formadores de opinião junto às políticas públicas de cunho ambiental implantadas pelo município. Outro objetivo era o de identificar possíveis ações ambientais desenvolvidas pela entidade, bem como o nível de conscientização da liderança local.

A comparação dos resultados das pesquisas dos dois bairros, somada à avaliação do planejamento das campanhas e às entrevistas com as lideranças locais, serviu de base para analisar os possíveis efeitos das ações de marketing ambiental da Saec na percepção da população sobre a questão do uso racional da água. Permitiu tambémavaliar se o nível de credibilidade do gestor público pode ter influenciado na adoção positiva das ideias da campanha por parte da população. Cabe ressaltar que se trata de um estudo de caso. Embora tenham sido analisadas, na medida do possível, a concretude e as perspectivas de se discutir o papel 
do marketing ambiental na agenda de uma gestão pública, não se pode extrair do mesmo conclusões generalizadoras.

\section{REVISÃO DE LITERATURA \\ Marketing Social Ambiental}

O marketing ambiental ou verde é um subgênero do marketing social, especializado apenas em questões de cunho ambiental. Segundo Kotler (1992), o marketing social consiste na aplicação de tecnologias próprias do marketing comercial na análise, planejamento, execução e avaliação de programas criados para influenciar o comportamento de determinados grupos sociais ou da população de um modo geral, com o objetivo de melhorar suas condições de vida.

Seus objetivos buscam estimular, induzir e facilitar a aceitação de ideias, crenças, hábitos, mitos, atitudes, ações, condutas, valores ou práticas sociais benéficas para a sociedade, como a preservação do meio ambiente, redução do consumo de água, etc. Nesse contexto, conforme Dias (2008), o produto social são as ideias, comportamentos e práticas que atendem à sociedade como um todo ou parte dela. As pessoas cujo comportamento se deseja influenciar podem ser denominadas clientes ou, como sugere Kotler (1992), adotantes das ações sociais.

O marketing em geral é estruturado a partir da contribuição de outros campos do conhecimento, como a antropologia, a economia, a sociologia, a psicologia e as teorias das comunicações. O marketing social apropria-se também desses conhecimentos para compreender o comportamento do consumidor e desenvolver com maior eficácia o processo de planejamento lógico que envolve, entre outras coisas, a segmentação de mercado, pesquisa orientada ao consumidor, identificação de estratégias e táticas, comunicação direta, testes de produtos e teorias de troca.

Por outro lado, o marketing social diferencia-se do marketing comercial na abordagem e na prática de valores que nem sempre são passíveis de adoção por parte do mercado, entre os quais se destacam: o valor da ação voluntária, o poder da intervenção humana, a sensação de autoeficácia e a importância de fornecer informações às pessoas sobre os produtos e/ou sobre elas mesmas.

Para Sina (1999), as principais características que distinguem o marketing social do marketing comercial são os seus propósitos, uma vez que seus benefícios visam, em primeira instância, ao indivíduo ou à sociedade. Andreasen (2002) difere o marketing social do comercial em dois principais aspectos. O primeiro vem de encontro à busca, por parte do marketing social, do bem-estar do indivíduo ou social, não simplesmente a satisfação pessoal. Segundo, a finalidade a ser alcançada nem sempre é identificada por aqueles que vivenciam o problema social e, dessa forma, muitas vezes a solução antecede a percepção do problema.

As diferenças apresentadas tornam difícil o sucesso de um programa de marketing social, pois seus objetivos dependem de atitudes que geralmente não são aceitas pela população, mesmo que sejam em seu benefício. Kotler (2008, p.208) cita algumas dessas atitudes: Desistir de um prazer (tome banhos mais rápidos); Ficar desconfortável (utilize cintos de segurança); Sair da rotina (pegue um ônibus para trabalhar); Resistir à pressão da sociedade (não comece a fumar); Escutar notícias ruins (faça um exame de HIV/ Aids); Estabelecer novos hábitos (caminhe até a padaria); Mudar um estilo de vida confortável (não ligue o ar-condicionado).

\section{Marketing social no setor público}

Segundo Sant'Anna (1998), a função do marketing no setor público é a de comunicar à população o que a administração pública deseja fazer ou já está fazendo, além de colher informações que tragam subsídios para traçar uma linha administrativa que atenda às reivindicações da população. Para o autor, a relação estabelecida entre a opinião pública e os governantes, por meio da comunicação, é um dos pilares da democracia moderna. Assim, prestar contas à população de seus atos e estimular o engajamento desta nas políticas adotadas é dever de todo governo que busque exercer uma administração transparente, em que a satisfação e o bem-estar do indivíduo são objetos da ação do Estado. 
Para Rego (1985), a comunicação pública é uma necessidade social. É o meio pelo qual os segmentos sociais tomam conhecimento das ações do governo e, por seu intermédio, transmitem aos governantes suas expectativas e desejos. É uma via de duas mãos onde os atores envolvidos (governo e população) se gerenciam e se relacionam. Segundo o autor, deve-se entender como comunicação pública a vasta rede formal criada e organizada no interior das organizações governamentais, com objetivo de levar à opinião pública fatos e informações de significação para a esfera pública.

Contudo, devido ao meio em que se estabelecem as relações desse tipo de marketing, perpetua certa confusão se o marketing social desenvolvido pelo setor público tem finalidades realmente sociais ou se figura simplesmente como marketing eleitoral. Segundo Manhanelli (2004), o marketing eleitoral diferencia-se do marketing social, em uma administração pública, porque seu objetivo é simplesmente o de convencer o eleitorado a votar neste ou naquele candidato. Dessa forma, são estratégias diferentes de marketing que podem estabelecer futuras conexões dependendo de conjunturas políticas, mas não podem ser consideradas como sinônimos.

Em Kotler (2008), o autor destaca o papel do marketing na gestão pública como a melhor plataforma de planejamento para atender às necessidades do cidadão e entregar-lhe resultados reais. Os governos que desenvolvem seus programas de marketing centrados no cidadão propiciam a utilização de serviços de forma mais ágil, eficiente e justa para a população como um todo. Kotler (2008, p.208) evidencia como o marketing social pode ser aplicado por uma gestão pública para beneficiar a comunidade: "...persuadindo os cidadãos a praticar o voluntariado, a serem mentores, a permanecerem na escola, a serem pais, a votar, a unirem-se em um programa de vigilância de bairro ou a se alistarem como doadores de órgãos".

Contudo, apesar de todos os princípios apresentados, para que o marketing público consiga irradiar mudanças, faz-se necessário total comprometimento e conhecimento por parte do gestor público. E, assim como qualquer ação de marketing, depende também de diversos instrumentos para ser impetrado com sucesso: parcerias estratégicas com outros setores sociais, comunicação em massa, eventos, campanhas continuadas de conscientização, assessoria de imprensa, etc. (Antoniosi, 2005).

A formação de parcerias estratégicas entre o setor público e os diversos setores sociais é fundamental para operacionalização e sucesso de grande parte das intervenções sociais. A ideia-chave é descobrir e conquistar os melhores parceiros para fazer com que as iniciativas ou necessidades do setor público aconteçam.

Segundo Kotler (2008), as parcerias estratégicas entre o setor público e o privado mostram sinais de crescimento nos últimos anos. Ao mesmo tempo, cada vez mais as corporações denotam extremo conhecimento e profissionalismo na tomada de decisões para a escolha de seus parceiros e iniciativas, selecionando apenas as ações com foco estratégico compatíveis com os valores de sua empresa e/ou aspirações de seus stakeholders. Independentemente da iniciativa, as corporações possuem uma série de recursos para contribuir com o setor público: dinheiro, habilidade, acesso a canais de distribuição, serviços gratuitos e doação de mercadorias.

As parcerias do setor público com organizações sem fins lucrativos também são numerosas e geralmente menos controvertidas que as parcerias com o setor privado. $\mathrm{O}$ chamado $3 .^{\circ}$ setor, apesar de não deter o mesmo poder de investimentos que o setor privado, tem muito a oferecer e a receber do setor público, uma vez que as organizações sem fins lucrativos detêmem seu corpo técnico importantes recursos de perícia, que podem ajudar as agências do governo na melhoria de seus programas, potencializando a satisfação do cidadão e reduzindo os custos das ações.

\section{Resultados}

As políticas públicas tendem a isolar a questão ambiental num departamento específico, numa secretaria ou num ministério e retiram a responsabilidade de outras instâncias emrelação ao meio ambiente. Para Dias (2009), esse sistema de isolamento vem mostrando sua ineficácia, visto que a problemática ambiental deve envolver os mais variados setores, particularmente aqueles relacionados com a política econômica e com as forças de mercado. O isolamento das políticas ambientais é preponderante para a manutenção da incapacidade dos órgãos estatais 
ou da sociedade embarrar os interesses econômicos em detrimento da exploração de recursos naturais.

Na esfera municipal, a Constituição Federal, por meio do artigo 225, ratificou a inclusão da temática ambiental nas Leis Orgânicas da maioria dos municípios, o que possibilitou a introdução de novas normas ambientais que podem gerar maior controle da sociedade sobre as fontes de poluição e degradação ambiental, como sanções administrativas, com aplicações de multa diárias e progressivas àqueles que tiverem condutas e exercerem atividades lesivas ao meio ambiente.

Contudo, os governos municipais nem sempre possuem capacidade de ação para atingir seus objetivos básicos e, segundo pesquisa divulgada pelo IBGE apud Dias (2009), em maio de 2005, grande parte dos municípios brasileiros não tem secretarias dedicadas exclusivamente a questões ambientais ou não possuem nenhum tipo de órgão para cuidar do meio ambiente. Também é possível constatar que, em inúmeros casos, a gestão ambiental se restringe às atividades de controle e fiscalização, quando na verdade é necessária a adoção de uma abordagem ambiental integrada, tendo como prioridade o desenvolvimento sustentável e a inclusão da variável ambiental no planejamento estratégico do município.
Diante do exposto, alguns municípios têm tomado medidas básicas que não envolvem onerosos recursos, mas necessitam de um eficiente trabalho de gerenciamento, como no investimento e capacitação técnica dos agentes administrativos da área ambiental, na integração das entidades ambientalistas e divisões ambientais de empresas num sistema de monitoramento permanente do meio ambiente, na efetuação de um levantamento rigoroso das condições ambientais do município e, principalmente, na busca de mecanismos de ação social que interajam e se relacionem com o ser humano, dos quais se podem citar principalmente a educação e o marketing ambiental.

No Brasil, a utilização de ferramentas de marketing ambiental em campanhas do setor público é superficial se comparada à grandeza do problema. Grande parte das ações é desenvolvida por empresas estatais como a Petrobrás, que, na maioria das vezes, prioriza o conteúdo informativo das próprias ações da empresa em detrimento de informações que poderiam ampliar o nível de informação da população e, consequentemente, conduzir a um processo de conscientização ambiental (Figura 1). Outras ações podem ser observadas emâmbito federal, mas é evidente que são motivadas pela pressão de ONGs ou de outros movimentos da sociedade civil (Figura 2).

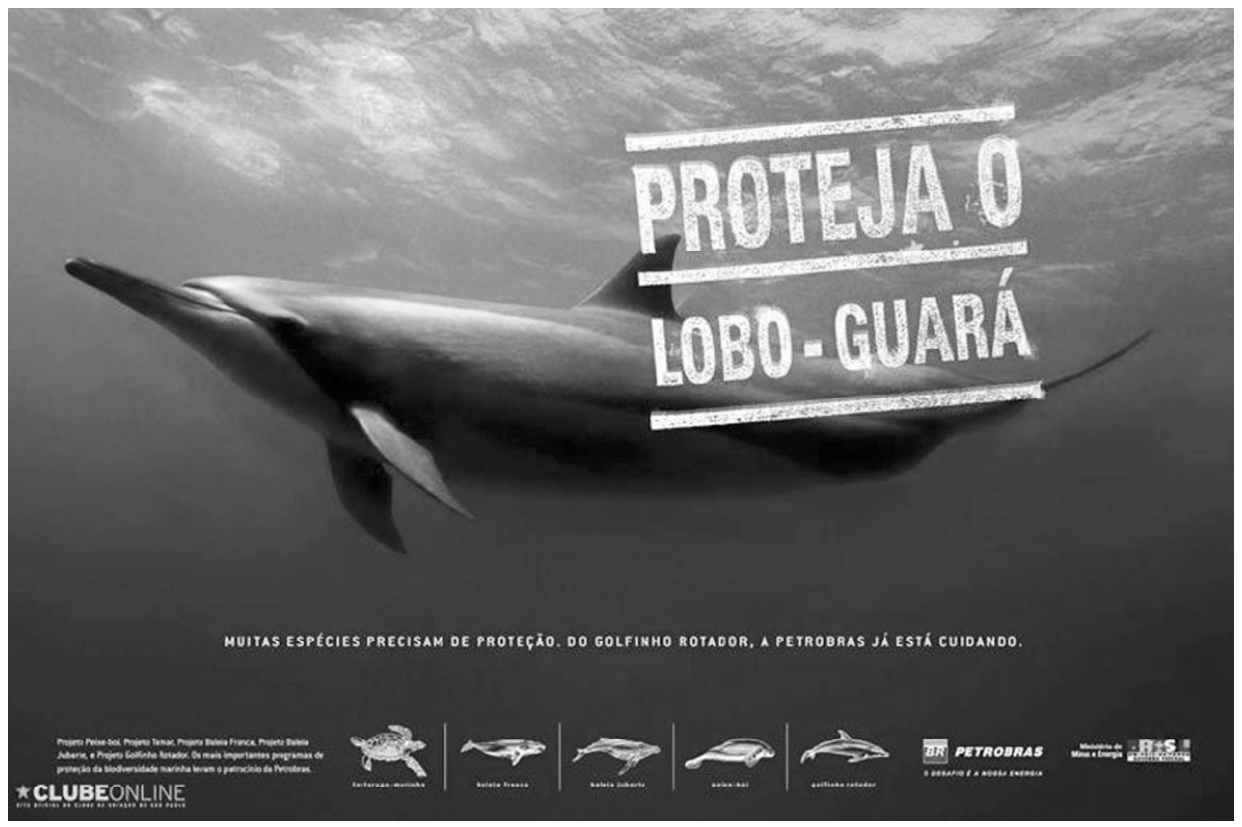

Figura 1 - Exemplo de campanha ambiental com conteúdo informativo da Petrobrás. 


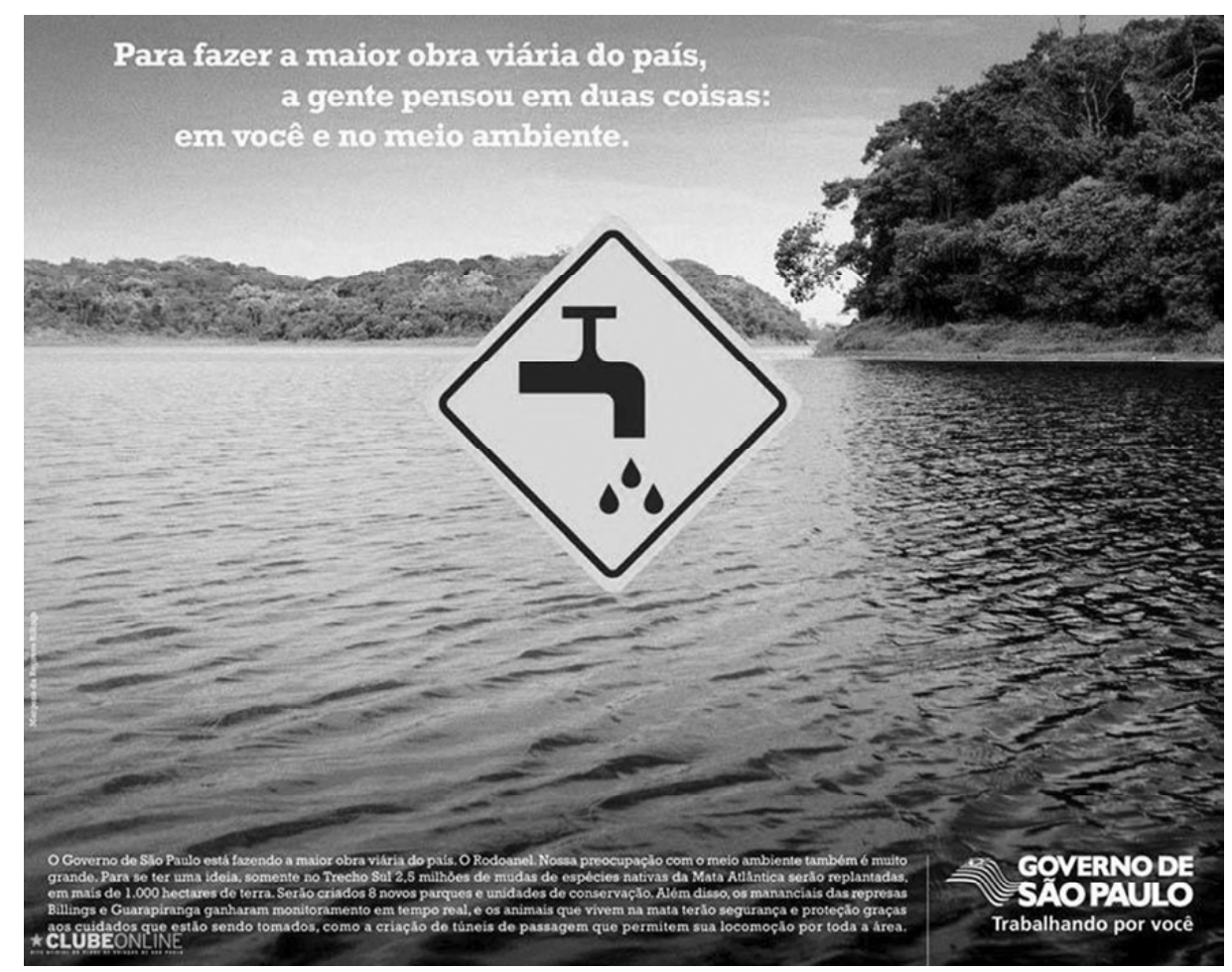

Figura 2 - Exemplo de campanha ambiental motivada em resposta às pressões de ONGs.

As ações de âmbito municipal, apesar da possibilidade de coexistirem com um problema local e terem, assim, maior facilidade de avaliar e planejar seus objetivos, atuam de forma isolada ou em continuidade às ações de outras esferas governamentais. Sempre limitadas aos contornos do município.

Kotler (2008) destaca o papel do marketing na gestão pública como a melhor plataforma de planejamento para atender às necessidades do cidadão e entregar-lhe resultados reais. Os governos que desenvolvem seus programas de marketing centrados no cidadão propiciam a utilização de serviços de forma mais ágil, eficiente e justa para a população como um todo.

Nesse aspecto, a Saec promoveu sete ações de marketing ambiental no período de janeiro de 2006 a novembro de 2009, com o objetivo de reduzir o consumo de água no município, sensibilizando a população sobre o problema do alto índice de consumo per capita de água no município, que em alguns bairros registra 240 litros por habitante, índice duas vezes maior que o indicado pela ONU.

Contudo, o número de ações de marketing com objetivo ambiental é inexpressivo se comparado às 1.750 ações desenvolvidas no município no mesmo período. A própria entidade desenvolveu outras 11 ações de marketing com finalidades informativas sobre o trabalho da Saec, sem nenhum teor ambiental. Vale ressaltar que o investimento para este grupo de ações representa $60 \%$ da verba destinada para o período. Nessa lógica, é possível diagnosticar que o investimento em comunicação para fins de conscientização ambiental foi secundário quando comparado à necessidade da entidade em expor para a população o trabalho executado em serviços essenciais, como obras de urbanização e saneamento (um exemplo de campanha desenvolvida pela Saec pode ser visto na Figura 3).

Esse, dentre outros fatos, denotam a ineficiência do governo municipal em conter a taxa de consumo de água na cidade; ao contrário, verifica-se que o consumo se intensificou principalmente na população mais abastada e esclarecida do município. Neste caso, as ações de marketing implementadas não apenas mostraram sua ineficiência, mas também evidenciam a má aplicação do dinheiro público. 


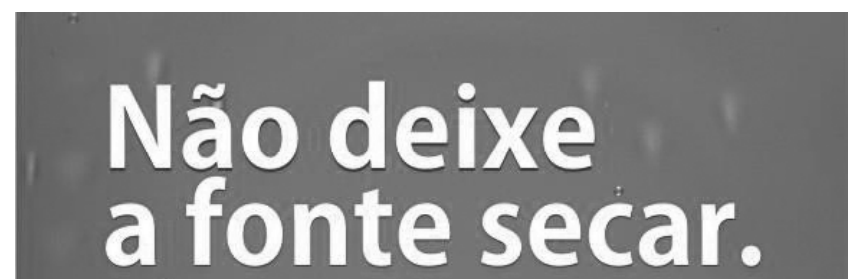

22 de março | Dia Mundial da Água

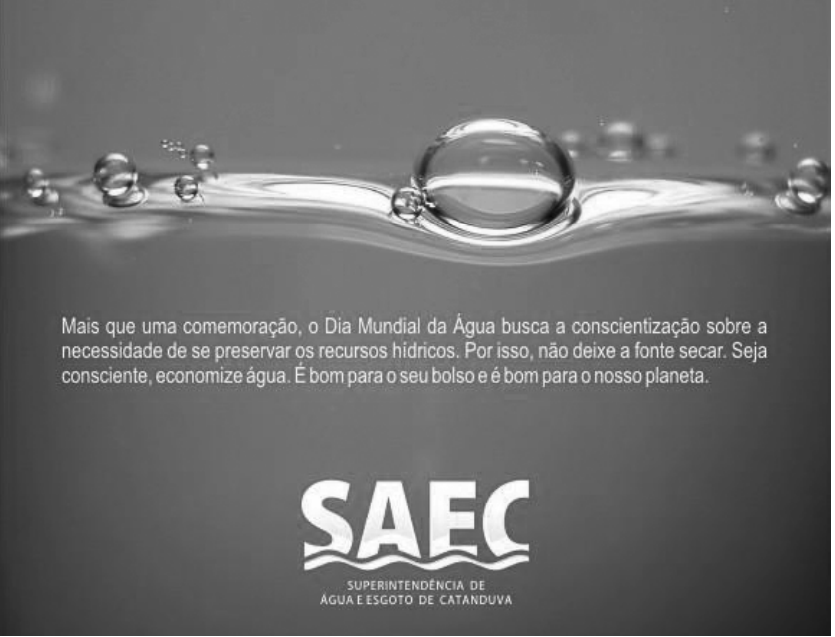

Figura 3 - Exemplo de campanha desenvolvida pela Saec com objetivo de conscientização da população.
Alguns fatos demonstram que a ineficiência das ações de marketing praticadas pelo órgão municipal foram norteadas por uma conjuntura de fatores que envolvem de forma dinâmica três atores sociais: a agência de comunicação, a entidade municipal e o público-adotante. No caso da Saec, foi possível diagnosticar que o planejamento é conduzido de forma casual, ou seja, quando há uma necessidade eminente (redução de consumo em período crítico, conscientização de algum hábito, etc.), a agência de comunicação é acionada para propor algum tipo de ação que objetive sanar o problema. Contudo, na ausência de um planejamento anual, as ações são desenvolvidas de forma desordenada e acabam por não priorizar pontos fundamentais para o sucesso da ação.

Na falta de um planejamento coeso, com a existência clara de um objetivo e da parcela da população que precisa ser contemplada pela comunicação, invariavelmente não há o controle dos investimentos das ações, fato que acaba por resultar em gastos abusivos em algumas e imperceptíveis em outras.

Como consequência, os gráficos a seguir (Figuras 4 e 5) mostram a promoção da mídia e da publicidade como principais agentes promotores de ações ambientais (nível local e global) e, ao mesmo tempo, ratificam o papel secundário do meio ambiente na agenda das políticas públicas.

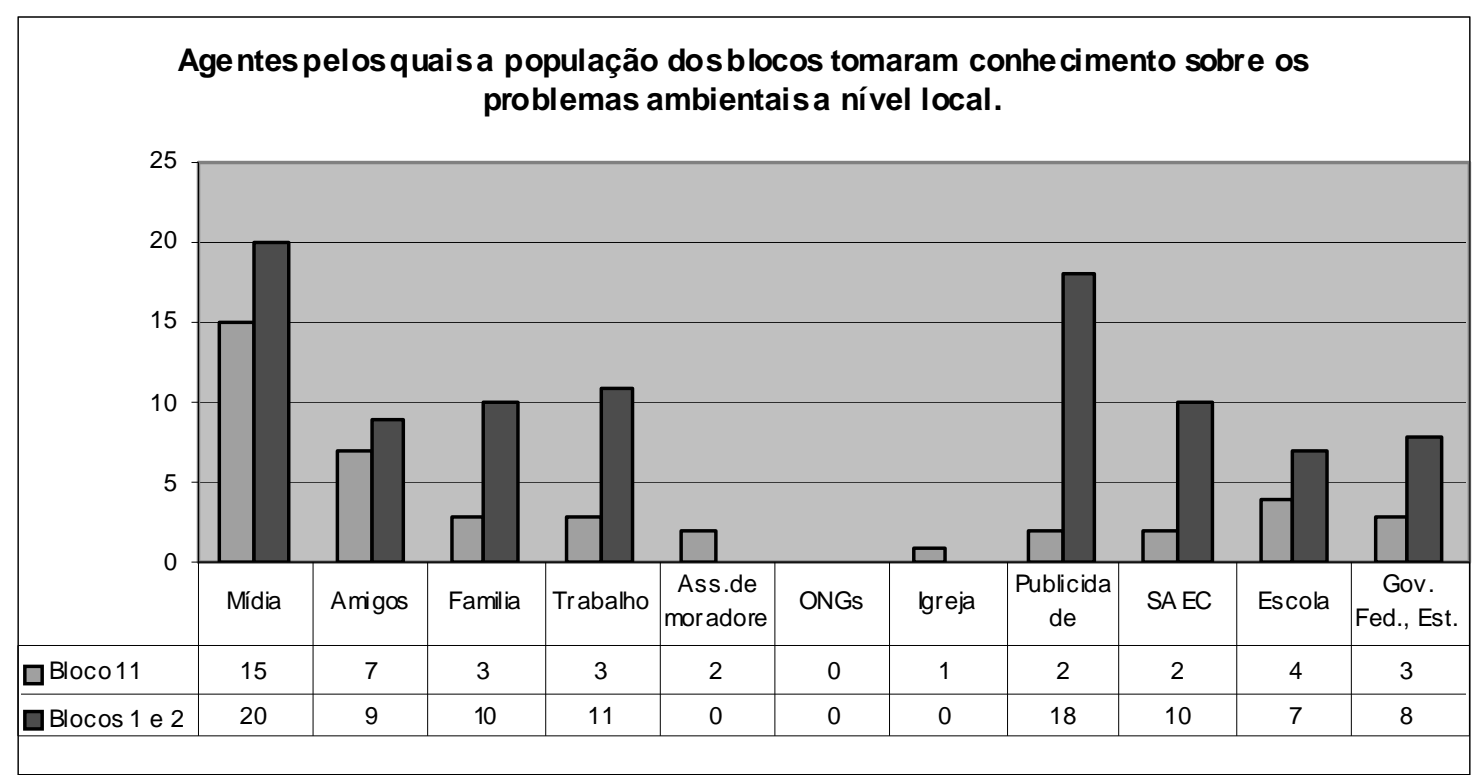

Figura 4 - Gráfico dos agentes disseminadores das ideias ambientais em nível local. 


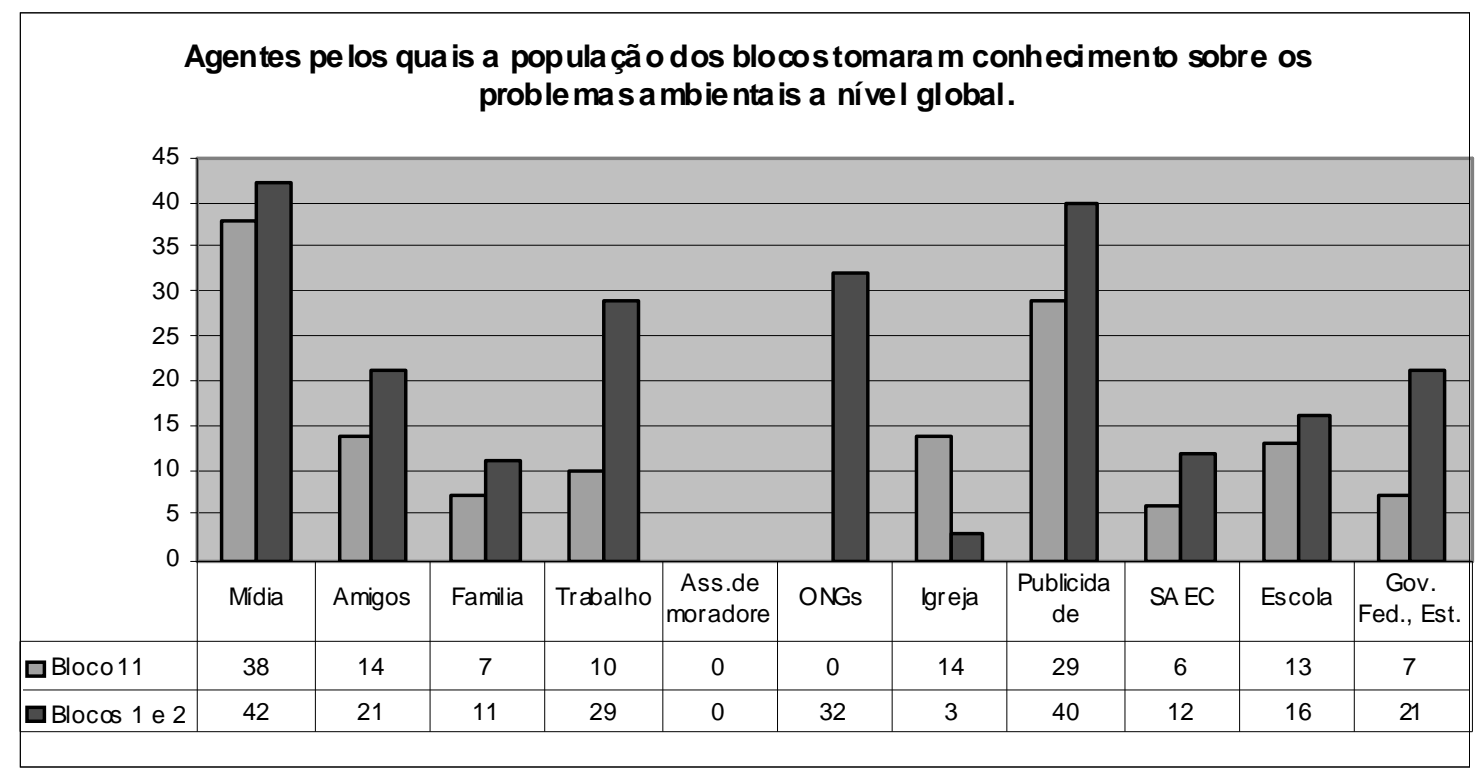

Figura 5 - Gráfico dos agentes disseminadores das ideias ambientais em nível global.

O dado indica que, mesmo quando uma das esferas se instaura como promotora dos meios publicitários ou midiáticos, seu índice de lembrança é baixo e acaba sendo ocultado pelo meio (no caso um outdoor, um anúncio de TV) ou pela mensagem (a ideia da campanha foi absorvida, mas quem a promoveu não ficou evidente).

A própria Saec, que na falta de organizações do terceiro setor na cidade deveria ser o principal agente na divulgação dos problemas ambientais de ordem local, foi pouco lembrada pela população do município. Vale considerar que nem todos os entrevistados tinham o conhecimento da existência da entidade: muitos pensavam que o antigo Departamento de Água e Esgoto - DAE ainda era o responsável pelo abastecimento do município.

Segundo a pesquisa realizada com os moradores do Bloco 11, a entidade ainda não é reconhecida por grande parte da população local. Apenas $48 \%$ dos munícipes dessa região já ouviram falar da Saec, sendo que grande parte destes reconhece o nome da instituição, porque a marca está impressa na conta de água. Dessa forma, pode-se supor que, nas classes menos abastadas da população, a instituição é associada apenas a valores negativos, já que o cidadão, sem conhecer o trabalho realizado pela entidade em seu benefício, apenas se lembra da marca como algo oneroso, negativo para sua vida.

Segundo Kotler (1992), a mensagem de comunicação ambiental, que se origina de uma campanha ou de uma empresa que goza de credibilidade e respeito, aumenta muitíssimo a probabilidade de o produto ambiental vir a ser adotado. Desse modo, é imprescindível que a Saec inicie, em caráter emergencial, um trabalho de posicionamento de marca, pois os resultados da comunicação dependem diretamente da credibilidade da entidade. Por outro lado, a pesquisa realizada nos Blocos 1 e 2-região central da cidade - mostrou que $76 \%$ dos entrevistados têm conhecimento sobre a entidade. Desse modo, pode-se sugerir que, na falta de ações de divulgação e posicionamento da marca da Saec, a imprensa local se torna, indiretamente, um meio eficaz de divulgação da superintendência. E, tendo como base que o acesso a este meio de comunicação é mais comum nas classes sociais mais abastadas, é possível concluir que o hiato da pesquisa existente entre os dois bairros é em função do acesso aos meios de comunicação, principalmente os meios impressos locais, fato que reflete a diferenciação socioeconômica dos munícipes. 
As entrevistas com os formadores de opinião também apontaram baixo poder de penetração das ações da Saec. Poucos se lembraram das ações e não acreditam que, perante seus conhecimentos sobre as realidades dos bairros, elas surtiriam algum efeito exponencial para a conscientização do consumo da água. Pode-se perceber pelas entrevistas que mesmo as lideranças locais têm muitas dúvidas sobre como trabalhar a questão com a comunidade.

Contudo, mais uma vez foram unânimes em afirmar que caso a entidade seja municiada de informação e capacitação de seu pessoal, eles poderiam contribuir com a Saec para a educação e conscientização do consumo no bairro onde atuam, mas infelizmente, até hoje, fora as escolas da rede pública, nenhuma entidade de bairro foi contatada pela superintendência com esses objetivos.

Segundo Crespo apud Trigueiro (2008), cada vez mais os brasileiros identificam no poder local o locus onde os problemas ambientais devem ser solucionados. Segundo pesquisa realizada pela autora para a série:
"O que os brasileiros pensam sobre meio ambiente e sustentabilidade", a responsabilidade atribuída às prefeituras cresceu de 30\% em 1992 para $46 \%$ em 2001. A responsabilidade atribuída a "cada um de nós" estacionou na casa dos $36 \%$.

A pesquisa com a população de Catanduva também aferiu a importância do governo municipal e da Saec como gestores ambientais quando avaliou quais as instituições em que o entrevistado confiaria para receber informações sobre o consumo consciente (Figura 6), sem temer que se trate de algo enganoso ou nocivo à sua familia. Este dado pressupõe que exista uma abertura em todas as camadas sociais para que as políticas públicas interajam nas questões sociais no cerne da vida do contribuinte - sua própria residência. Alguns entrevistados afirmaram que guardaram a cartilha distribuída em 2006 pela Secretaria de Saneamento Básico por um período após a campanhae que gostariam de receber novas e atualizadas cartilhas, mas que não guardariam se o material enviado fosse de uma empresa.

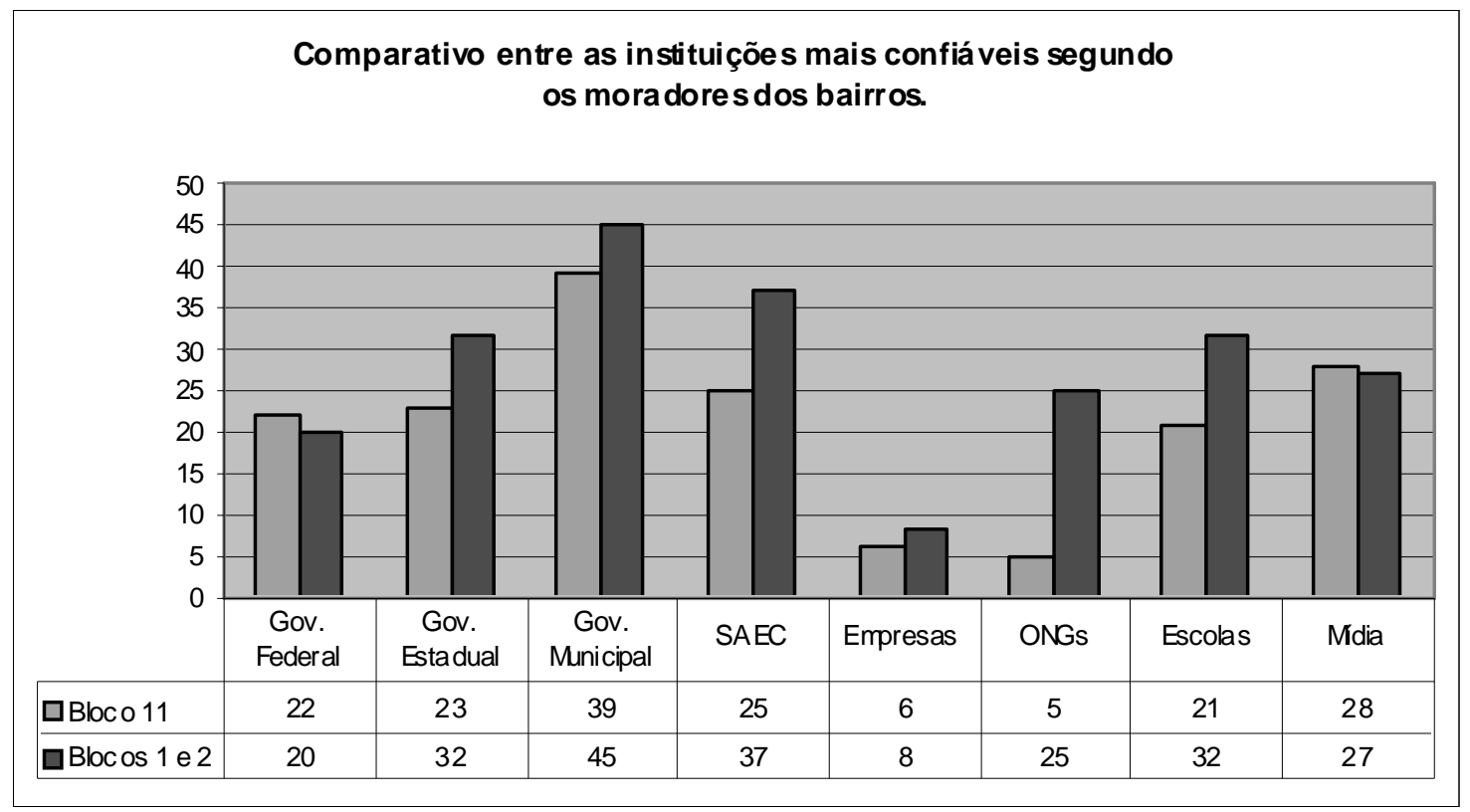

Figura 6 - Gráfico comparativos das instituições mais confiáveis.

Nas ações de marketing ambiental da Saec, a temática "consumo local" foi abordada em apenas três das sete ações. O dado denota que os objetivos de comunicação das ações da entidade não levaram em consideração a problemática ambiental local, onde os atores sociais estão envolvidos e podem interagir com o processo. 
Isso já elimina várias barreiras na condução do processo de conscientização ambiental, entre as quais é possível citar: (1) barreira espacial: a falta d água em outras regiões do Brasil ou do planeta não indicam que a água faltará também no município, mas o indício de possíveis cortes de água na rede municipal, caso não haja imediata redução do consumo, pode afetar diretamente a vida do cidadão; (2) barreira temporal: as imagens difundidas pela mídia de rios e cachoeiras, onde as águas escoam em abundância, levam à crença de que, mesmo que a água acabe, o processo levará milhares de anos e, por conta disso, tal fato não o atingirá.

O gráfico anexo (Figura 7) identifica o baixo índice de conhecimento da população quanto aos problemas ambientais do município, em comparação com os problemas ambientais globais.

Os formadores de opinião locais também responderam que desconhecem os possíveis problemas de falta da água na cidade. Quando entrevistados, citaram apenas as preocupações com os problemas globais e algumas ações locais sem ligação direta com a temática conscientização, como o tratamento de esgoto do bairro e a despoluição do ribeirão São Domingos. Vale citar que os entrevistados desconhecem a realidade de consumo de água nos bairros onde atuam, mas creditam, assim que informados sobre os números de consumo, motivo latente à falta de conscientização.

Esses dados transferem ao primeiro setor o importante papel de protagonista da causa ambiental e ratificam a eminente necessidade de intervenção do Estado, por meio de políticas públicas que evidenciem a importância da conscientização local do consumo da água, seja através de ações de marketing, educação ambiental nas escolas ou até mesmo da elevação do custo da água. A barreira existente entre o consumidor e o produto fomenta a desvalorização do mesmo e, consequentemente, propicia sua desvalorização e seu uso inadequado.

\section{CONSIDERaÇõES FINAIS}

As questões levantadas no decorrer deste artigo tangenciam alguns pontos relevantes da atuação do marketing ambiental emuma gestão pública municipal. Entretanto, não é pretensão deste trabalho - um estudo de caso que tem limites e potencialidades - o esgotamento do assunto, visto que é um tema mutante e condicionado à ação de diversos fatores externos, como as leis de mercado, políticas públicas e, principalmente, o perfil social no qual a questão está inserida. Desse modo, seguem alguns pontos relevantes que cumprem o papel de considerações finais.

Um dos propostos iniciais desta pesquisa era a compreensão do papel das políticas públicas locais em relação às ações ambientais, em que vários setores sociais interagem de forma direta ou indireta.

Nesse sentido, o processo de instauração de uma nova consciência ambiental, como objetivo de provocar mudanças cognitivas, valores, comportamento ou ação, deve contemplar, sobretudo, as realidades locais nas quais o cidadão está inserido. Tais dados transferem às políticas públicas locais a missão de arquitetar ações juntamente comos demais setores sociais, no intuito de promover a reorganização do espaço ambiental local, conscientizando os cidadãos das necessidades de mudanças de hábitos baseadas em suas realidades e modos de vida.

A proximidade do poder público municipal com a realidade local facilita e propicia ao cidadão o entendimento das consequências diretas de seus atos, ou seja, se faltar água na sua cidade ou se o rio estiver poluído, ele sabe que foi um dos responsáveis pela situação. Dessa forma, este trabalho sugere que a barreira "espacial" existente entre o consumidor e o produto fomenta a desvalorização do mesmo e pode propiciar o seu uso inadequado. Cabe então ao poder público a valorização do espaço local como parte integrante de um plano macro, em que todas as pessoas afetam e são afetadas por suas ações.

Nesse encalço, o setor público municipal de Catanduva busca formas de interação com as populações locais, seja por meio da educação ambiental, seja pela coibição e/ou penalização de más práticas contra o meio ambiente. Conforme dados da pesquisa de campo, os entrevistados creditam confiança 
ao governo local na promoção de ações pró-ativas ambientais, sem temer que se trate de algo enganoso ou nocivo à sua família. $\mathrm{O}$ índice de aceitação das políticas públicas locais é maior que os resultados obtidos por outras instituições que gozam de credibilidade, como as ONGs, escolas e outras esferas governamentais.

Entretanto, a taxa de consumo de água no município não foi contida pelas ações governamentais; ao contrário, o consumo se intensificou principalmente na parcela da população mais abastada e esclarecida da cidade. Além disso, os entrevistados mostraram desconhecer as ações da entidade e, muitas vezes, a própria entidade.

Nesse caso, as ferramentas de marketing implementadas pelo poder público municipal não apenas mostraram sua ineficiência, mas também evidenciam a má aplicação do dinheiro público. Alguns fatos evidenciam que a ineficiência das ações de marketing praticadas pelo órgão municipal foram norteadas por uma conjuntura de fatores que envolvem de forma dinâmica três atores sociais: a agência de comunicação, a entidade municipal e o público-adotante.

No caso da Saec, foi possível diagnosticar que o planejamento é conduzido de forma casual, ou seja, quando há uma necessidade eminente (redução de consumo em período crítico, conscientização de algum hábito, etc.), a agência de comunicação é acionada para propor algum tipo de ação que objetive sanar o problema. Contudo, na ausência de um planejamento anual, as ações são desenvolvidas de forma desordenada e acabam por não priorizar pontos fundamentais para o sucesso da ação.

Na falta de um planejamento coeso, coma existência clara de um objetivo e da parcela da população que precisa ser contemplada pela comunicação, invariavelmente não há o controle dos investimentos das ações, fato que acaba por resultar em gastos abusivos em algumas e imperceptíveis emoutras.

Além disso, a literatura consultada apresenta a importância do planejamento para a distribuição coerente entre os períodos das campanhas, uma vez que mudança de comportamento pelos adotantes depende de vários processos cognitivos, que demandam tempo e grande frequência de informação. $\mathrm{O}$ grande hiato de informações distancia o receptor da mensagem e torna a comunicação ineficiente. Podemos observar que, no caso da Saec, a distribuição e a escolha dos períodos das ações são fundamentadas por suposições dos gestores da própria entidade, baseados apenas nos dados de consumo do município, sem particularizar e diferenciar o consumo, formas de uso e hábitos dos diversos setores.

Nessas condições, é plausível que a dificuldade de penetração das campanhas seja natural. Como já visto, a aceitação dos elementos condicionantes, que possibilitem a mudança de hábito do cidadão, não é uma barreira fácil de transpor. Se os gestores municipais pretendem utilizar a comunicação como ferramenta que auxilie na transposição dessas barreiras, é necessário que saibam como manuseá-la ao seu favor e, sobretudo, que invistam muito em educação ambiental.

$\mathrm{O}$ que ficou claro no decorrer do processo de desenvolvimento deste trabalho é que a motivação para a construção de uma nova ordem ambiental ainda não é o foco das preocupações do setor público municipal. As intervenções propostas aparentam mais sanar um anseio social do que realmente contribuir para uma nova cultura ambiental.

Contudo, pode-se aferir que as ferramentas de comunicação podem e devem contribuir para as intervenções ambientais dos municípios de médio porte como Catanduva. Outros fatores são circunstanciais para que o investimento seja revertido em resultados para a administração pública, entre eles o distanciamento político somado à independência de gestão da entidade frente à administração pública e, por fim, uma relação estreita e transparente com uma agência de comunicação capaz de gerir os anseios e necessidades do órgão público no desenvolvimento de um plano de comunicação melhor fundamentado, no qual o meio ambiente seja efetivamente incorporado à agenda das gestões municipais.

Situação esta que não pode prescindir de um investimento continuado na educação ambiental, com a ressalva de que o mesmo não deve submeter-se à 
lógica do mercado, a qual, via de regra, transforma as relações entre as pessoas em operações entre mercadorias, o que contraria uma das diretrizes deste trabalho, indicativas do difícil e necessário processo de mudanças e de formação de consciências.

\section{REFERÊNCIAS}

ANDREASEN, Alan R. Ética e marketing social. São Paulo: Futura, 2002. 245p.

ANTONIOSI, Luciana. Marketing político em uma gestão participativa: um estudo de caso da Prefeitura Municipal de Matão-SP. 2005. 140f. Dissertação (Mestrado em Desenvolvimento Regional e Meio Ambiente). UNIARA, Araraquara, 2005.

BOFF, Leonardo. Ética e moral: a busca dos fundamentos. Petrópolis: Vozes, 2003. 125p.

CAETANO, Joaquim. SOARES, Marta. DIAS, Rosa. JOAQUIM, Rui. GOUVEIA, Tiago Robalo. Marketing Ambiental. Corroios: Plátano Editora, 2008. 160p.

CAPRA,Fritjof. Alfabetização ecológica: o desafio para a educação do século 21. In: TRIGUEIRO, André. Meio ambiente no século 21: 21 especialistas falam da questão ambiental nas suas áreas de conhecimento. 5. ed. Campinas: Armazém do Ipê (Autores Associados), 2008. 367 p. cap. 1, p. 19-33.

CRESPO, Samira. Uma visão sobre a evolução da consciência ambiental no Brasil nos anos 1990. In: TRIGUEIRO, André. Meio ambiente no século 21: 21 especialistas falam da questão ambiental nas suas áreas de conhecimento. 5. ed. Campinas: Armazém do Ipê (Autores Associados), 2008. 367 p, cap.4, p. 59-74.

DIAS, Reinaldo. Marketing ambiental: ética, responsabilidade social e competitividade nos negócios. 1.ed. São Paulo: Atlas, 2008. 200p.

\section{.Gestão Ambiental:}

Responsabilidade sociale sustentabilidade. São Paulo: Atlas, 2009. 196 p.

FONTES, Miguel. Marketing Social: novos paradigmas. Brasília: Elsevier, 2008.

GIACOMINI FILHO. Meio ambiente e consumismo. 1.ed. São Paulo: SENAC, 2008. $255 \mathrm{p}$.

KOTLER, Philip; ROBERTO, Eduardo L. Marketing social: estratégias para alterar o comportamento público. Rio de Janeiro: Campus, 1992. 392p.

OTTMAN, JACQUELYNA. Marketing verde: desafios e oportunidades para nova era do marketing. 2.ed. São Paulo: Makron, 1994. 270p.

MANHANELLI, Carlos Augusto. Marketing póseleitoral. 1.ed. São Paulo: Summus, 2004. 118p.

SANT'ANNA, Armando. Propaganda: teoria, técnica e prática. 7.ed. São Paulo: Pioneira, 1998. $469 \mathrm{p}$.

SINA, Amália; SOUZA, Paulo de. Marketing Social: uma oportunidade para atuar e contribuir socialmente no Terceiro Setor.. São Paulo: Crescente Editorial, 1999. 192p.

REGO, Francisco Gaudêncio Torquato do. Marketing Político e Governamental. 2.ed. São Paulo: Summus Editorial, 1985. 85p.

TRIGUEIRO, André (coord). Meio ambiente no século 21: 21 especialistas falam da questão ambiental nas suas áreas de conhecimento. Campinas: Armazém do Ipê (Autores Associados), 2008. 


\section{Anexo}

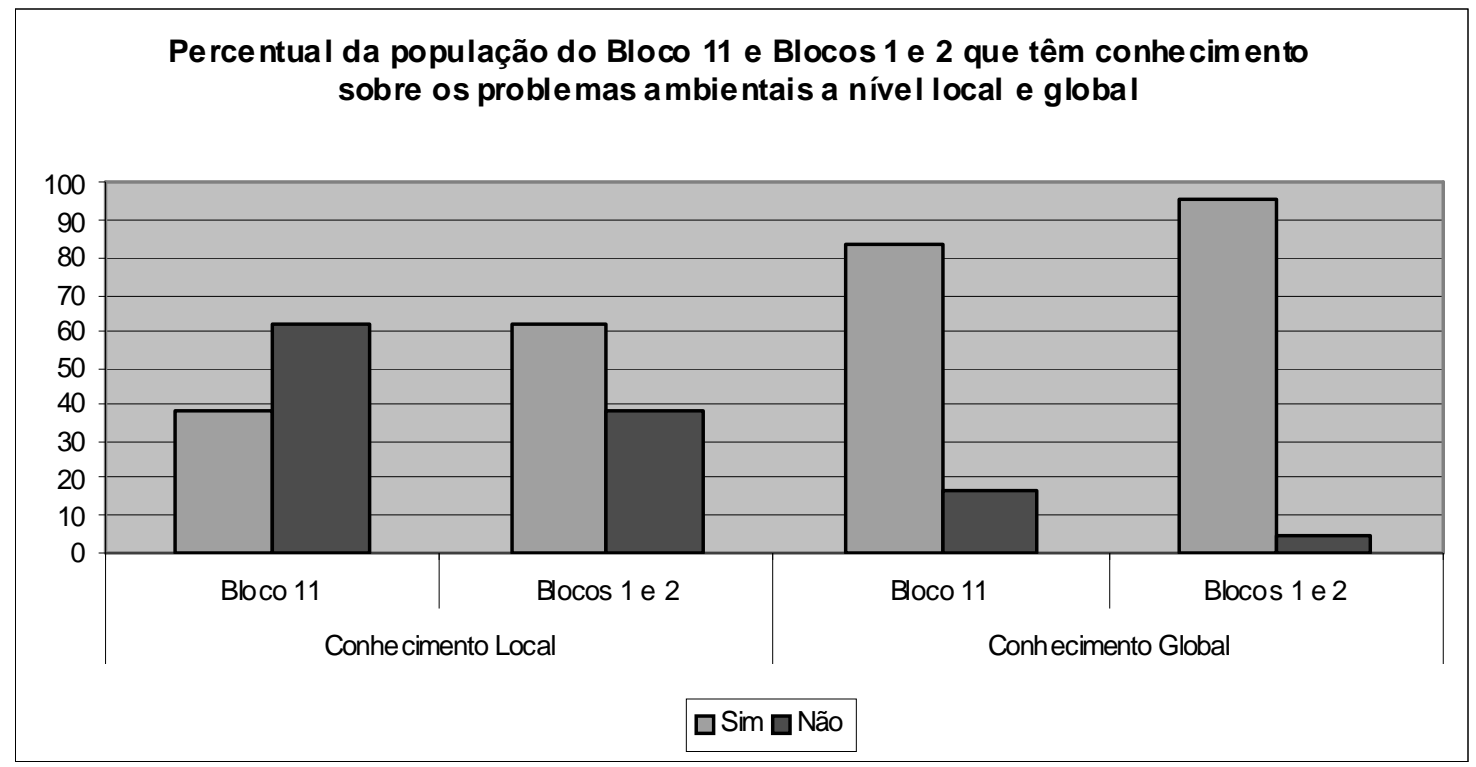

Figura 7 - Gráfico da população dos blocos que têm conhecimento sobre os problemas ambientais.

RECEBIDO EM 27/10/2010

ACEITO EM 21/11/2010 